\title{
Analysis of cystic hygroma diagnosed in the first trimester: Single-center experience
}

\author{
(D) Betül Yakıştıran ${ }^{1}$, (D) Orhan Altınboğa ${ }^{1}$, (D) Emre Canpolat ${ }^{2}$, (D) Esra Şükran Çakar ${ }^{3}$, (D) Şevki Çelen ${ }^{1}$, \\ (D) Ali Turhan Çağlar1, (D) Yaprak Engin Üstün4 \\ 1Department of Obstetrics and Gynecology, University of Health Sciences, Ankara Zekai Tahir Burak Women's Health \\ Training and Research Hospital, Ankara, Turkey \\ 2Department of Pediatrics, University of Health Sciences, Ankara Zekai Tahir Burak Women's Health Training and Research \\ Hospital, Ankara, Turkey \\ 32Department of Genetic, University of Health Sciences, Ankara Zekai Tahir Burak Women's Health Training and Research \\ Hospital, Ankara, Turkey \\ ${ }^{4}$ Department of Obstetrics and Gynecology, University of Health Sciences Turkey, Ankara Etlik Zubeyde Hanım Women`s \\ Health and Research Center, Ankara, Turkey
}

\section{Abstract}

Objective: To evaluate the obstetric outcomes of fetuses with cystic hygroma other than karyotype abnormalities and structural malformations.

Material and Methods: We conducted a retrospective study based on the review of medical records of pregnant women in whom ultrasonographic diagnosis of fetal cystic hygroma was established in the first trimester from January 2014 to October 2018 . All patients were offered genetic counselling and prenatal invasive diagnostic procedures to obtain fetal karyotype. For ongoing pregnancies fetal echocardiography and detailed second trimester sonographic anomaly screening was performed by a perinatologist/pediatric cardiologist. The demographic characteristics of the women and the results of the karyotype analysis were obtained from the database of our hospital and correlated with the obstetric outcomes.

Results: Within a five-year period, there were 106 cases of fetal cystic hygroma. Of those, fetal cardiac malformations were detected in four and micrognathia in one fetus. Eighty-five women underwent fetal invasive procedures and karyotype abnormalities were detected in 52 of the cases. Fetal outcomes of 33 cases with normal karyotype and 21 cases in whom karyotyping analysis were not performed due to patient refusal were enrolled into the study. Obstetric outcomes of 21 women who refused karyotyping consisted of 13 livebirths, seven missed abortions, and one fetal death, whereas those of 33 women with normal karyotype were; 12 livebirths, 12 missed abortions, two hydrops fetalis, and five fetal deaths. Nineteen of 33 fetuses with a normal karyotype and eight of 21 fetuses in whom karyotyping was not performed were terminated.

Conclusion: The presence of cystic hygroma carries a high risk for fetal karyotype abnormalities and cardiac malformations. The postnatal outcomes of the fetuses with cystic hygroma appeared to be correlated with the absence of structural malformations and karyotype abnormalities. (J Turk Ger Gynecol Assoc 2020; 21: 107-10)

Keywords: Cystic hygroma, perinatal outcomes, prenatal diagnosis

Received: 20 January, 2019 Accepted: 10 July, 2019

\section{Introduction}

Cystic hygroma is a congenital malformation characterized by the presence of abnormal fluid collection at sites of lymphaticvenous collection within the neck, mediastinum, abdomen, and axillary region (1). It is also defined as a subgroup of lymphangiomas with the cystic variety, filled with proteinrich fluid (2). Cystic hygroma is classified as septated and non-septated. The overall incidence of cystic hygroma is approximately $1 / 1000-6000$ births and 1/750 spontaneous abortions (3). 
Cystic hygromas of nuchal origin are reported to be associated with fetal aneuploidy and structural anomalies in $50-80 \%$ of cases (1). Association with aneuploidy and/or fetal structural abnormalities worsens the prognosis. This condition can be diagnosed with sonography during fetal nuchal translucency measurement in the mid-sagittal plane in the first or early second trimester. When a cystic hygroma is diagnosed, the fetus should undergo thorough anatomic scanning for other system anomalies. In the next step, the parents should be offered invasive procedures for fetal karyotype analyses in order to detect any chromosomal abnormalities (4). If they accept karyotype analyses, chorion villus sampling or amniocentesis should be performed by a perinatologist.

Previous studies reported poorer perinatal outcomes in pregnancies with fetal cystic hygroma and associated aneuploidy $(5,6)$. We conducted this retrospective study to evaluate the pregnancy outcomes of fetuses with cystic hygroma either with normal karyotype or with no karyotype analysis in the prenatal period.

\section{Material and Methods}

All procedures involved performed in studies involving animals and humans were in accordance with the ethical standards of the institution or practice at which the studies were conducted. A retrospective cohort based on a review of medical records of patients with fetal cystic hygroma, diagnosed and/or referred to our hospital, between January 2014 and October 2018 was conducted. All scans were performed using a Voluson ${ }^{\text {тм }} 730$ Pro (GE Healthcare, USA) multifrequency convex transducer at 2.0-7.0 MHz. Cystic hygroma was defined as an enlarged sonolucency with clearly visible septations extending along the fetal body axis, in contrast to nuchal translucency, which was described as a non-septated sonolucent area confined to the fetal neck. They were differentiated from nuchal edema by the presence of the nuchal ligament. Upon diagnosis of cystic hygroma, all patients were provided genetic counselling. Prenatal invasive diagnostic procedures were offered for fetal karyotyping. A complete fetal anomaly scanning was then performed for the detection of other associated structural anomalies. Women who wanted to continue their pregnancies with cystic hygroma with normal karyotype and undetermined karyotype/due to the fact that parents did not accept the invasive procedures were enrolled into the study. For those women, fetal echocardiography and second trimester detailed sonographic evaluation were performed by a perinatologist.

The demographic characteristics of the patients, and results of the fetal karyotypes were recorded from the electronic database of the hospital. Pregnancy outcomes were tabulated from electronic records of the hospitals, and for women who did not deliver at our hospitals, telephone interviews for the pregnancy outcomes were made. Moreover, physical examination findings of the infants were also performed by inviting them to the hospital.

\section{Statistical analysis}

Data were calculated using the SPSS 11.5 software package for Windows (SPSS Inc., USA). Descriptive statistics are presented as mean \pm standard deviation and median (minimummaximum) and percentages.

\section{Results}

Within this five-year period, there were 106 cases of fetal cystic hygroma; 85 women underwent karyotype analysis, whereas 21 refused karyotype analysis.

The demographic characteristics of the women are depicted in Table 1. The median maternal age was 35 (range, 22-40) years. Among them, a normal karyotype was revealed in 33 (38.8\%) cases. In the remaining 52 (61.2\%), fetal karyotype abnormalities were detected and they were excluded from the study. Thus the study population included the outcomes of 54 fetuses with cystic hygroma in whom invasive diagnostic procedures were either not performed $(n=21)$ or normal $(n=33)$.

The flow chart of the evaluation of the women with hydrops fetalis together with the details of the karyotype abnormalities, fetal structural abnormalities, and pregnancy outcome are summarized in Figure 1. Associated structural anomalies were present in $7(12.9 \%)$ cases, including hydrops fetalis $(n=2 ; 28.6 \%)$, transposition of the great arteries (TGA) $(n=2$; $28.6 \%)$, perimembranous ventricular septal defect (VSD) $(n=1$; $14.3 \%)$, atrioventricular septal defect (AVSD) $(n=1 ; 14.3 \%)$, and micrognathia $(\mathrm{n}=1 ; 14.3 \%)$.

In the group that refused karyotype analysis $(n=21)$, pregnancy outcomes were as follows: 13 live births ( $n=11$ vaginal births; $n=2$ cesarean deliveries), seven missed abortions, and one intrauterine death. In the other group with normal fetal karyotype $(n=33)$,

Table 1. Demographic characteristics of study group

\begin{tabular}{|c|c|c|c|c|}
\hline & \multicolumn{2}{|c|}{$\begin{array}{l}\text { Pregnants underwent } \\
\text { invasive sampling } \\
(n=85)\end{array}$} & \multicolumn{2}{|c|}{$\begin{array}{l}\text { Pregnants refused } \\
\text { invasive sampling } \\
(n=21)\end{array}$} \\
\hline & Mean \pm SD & $\begin{array}{l}\text { Median } \\
\text { (min-max) }\end{array}$ & Mean \pm SD & $\begin{array}{l}\text { Median } \\
\text { (min-max) }\end{array}$ \\
\hline $\begin{array}{l}\text { Age, } \\
\text { years }\end{array}$ & $32.00 \pm 7.21$ & $35(22-40)$ & $31.00 \pm 5.22$ & 32 (24-38) \\
\hline Gravida & $2.00 \pm 0.80$ & $2(1-3)$ & $2.00 \pm 0.62$ & $2(1-3)$ \\
\hline Parity & $1.86 \pm 0.69$ & $2(1-3)$ & $1.80 \pm 1.00$ & $2(1-3)$ \\
\hline Abortus & $0.43 \pm 0.53$ & $0(0-1)$ & $0.20 \pm 0.35$ & $0(0-1)$ \\
\hline $\begin{array}{l}\text { Live } \\
\text { birth }\end{array}$ & $1.71 \pm 0.76$ & $2(1-3)$ & $0.81 \pm 0.42$ & $1(1-2)$ \\
\hline
\end{tabular}




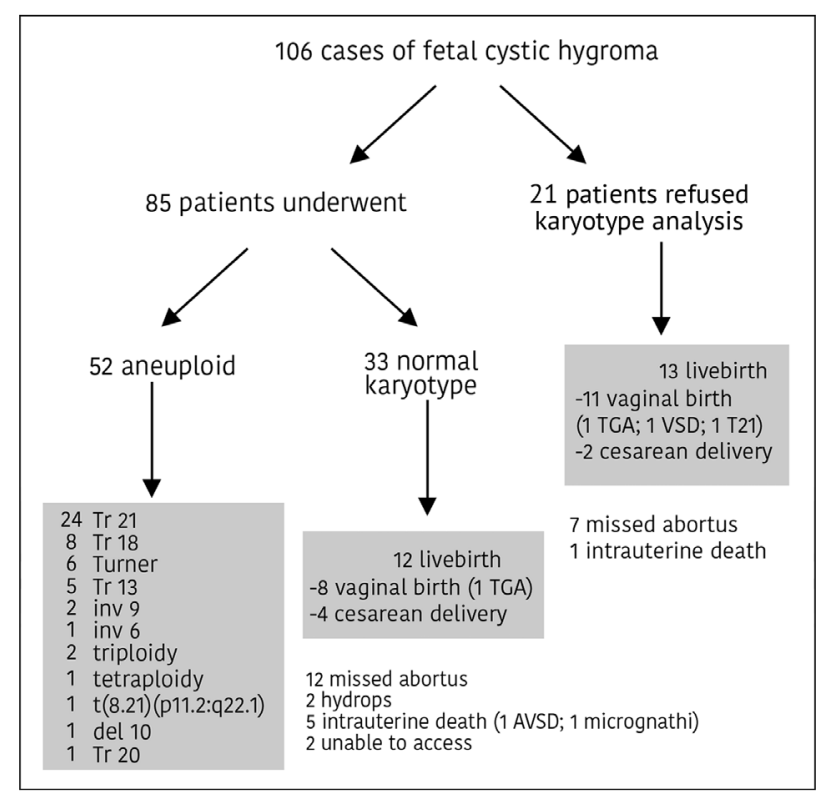

Figure 1. Overall outcomes from the prenatally diagnosed cases of cystic hygroma

pregnancy outcomes included 12 live births ( $\mathrm{n}=8$ vaginal births; $\mathrm{n}=4$ cesarean deliveries), 12 missed abortions, two hydrops, and five fetal deaths. We were unable to obtain the results about pregnancy outcomes in two fetuses with cystic hygroma with normal karyotype. Second trimester pregnancy termination was performed on 19 women with fetal cystic hygroma with normal karyotype and eight of 21 women who refused karyotyping. Two newborns with cardiac malformation died within the first week of delivery. Both of these cases were TGA. Follow-up of the 23 infants continued for nearly 36 months. Only one infant underwent surgery due to congenital hip dislocation. Regarding the 13 live births that refused karyotyping in utero, and were karyotyped postnatally; one infant was trisomy 21 and the remaining 12 infants were euploid. No neurologic developmental disorders were detected in any infants excluding the infant with trisomy 21.

\section{Discussion}

This study once again confirms the fact that increased nuchal translucency in first trimester screening is associated with chromosomal abnormalities, structural malformations, and fetal demise. The overall probability of live births for both groups was $23.5 \%$, and after the exclusion of aneuploid fetuses, it was $46.3 \%$. Bilardo et al. (7) reported these rates as $43.2 \%$ and $68.1 \%$, respectively, for increased nuchal translucency groups. On the other hand, the live birth rates of women who refused karyotyping prenatally was $61.9 \%(n=13 / 21)$, and the overall chance of live birth in the total group was $12.3 \%(n=13 / 106)$.

Nuchal translucency is an essential part of the screening for chromosomal anomalies on routine or indicated first trimester fetal sonographic assessment. During fetal nuchal translucency measurement in the mid-sagittal plane, we should keep in mind the association between increased nuchal translucency and chromosomal abnormalities, congenital malformations or several genetic syndromes (8). When a cystic hygroma is diagnosed, detailed ultrasound examination and fetal chromosomal analyses are indicated due to the high rates of fetal aneuploidy and coexisting structural malformations (9). Despite invasive prenatal diagnostic procedures for fetal karyotyping and parental counseling about poor fetal prognosis, parents sometimes refuse these procedures due to religious beliefs, and the increased risk of abortion with invasive fetal procedures. Even if normal karyotype is reported due to the limited treatment modalities and possibility of unfavorable consequences, the parents can opt for elective termination.

Previous studies indicated that cystic hygroma with fetal structural abnormalities is associated with poor fetal outcomes (1-6). The most frequent fetal structural malformation is cardiac defects within euploid groups. TGA has the highest incidence (90\%) in this group. Septal or valvular defects are present in $43 \%$ and aortic valve/isthmus stenosis is present in $86 \%$ of cardiac abnormalities (7). We found that the overall frequency of cardiovascular anomalies in our study group was $7.4 \%$. Among the cardiac defects, TGA, perimembranous VSD, and AVSD were detected with a frequency of $28.6 \%, 14.3 \%$, and $14.3 \%$, respectively, emphasizing the fact that in the second trimester, targeted fetal echocardiographic examinations are important and an essential diagnostic tool in euploid fetuses with cystic hygroma $(1,7)$.

Hydrops fetalis is another important prognostic marker. Bernard et al. (10), reported a mortality rate of $96.5 \%$ in hydropic fetuses. Our findings showed that the incidence of fetal death with coexisting hydrops was $100 \%$. Generalized edema and hydrops may be the cause of left atrium dysfunction and aorta due to a compression effect leading to fetal death. In the literature, only a few studies have reported the resolution of hydrops and healthy newborns (11); the majority of the studies demonstrate that hydrops is associated with poor fetal outcomes $(6,10,12,13)$. On the other hand, the resolution of nuchal edema with a normal karyotype is a good prognostic marker in the absence of any coexisting malformation. Two fetuses with hydrops fetalis were present in our study. Cardiac malformations were detected more frequently than hydrops fetalis. Cardiac malformations, arrhythmia, aneuploidy, and fetal structural malformations may lead to non-immune hydrops fetalis (14). Our findings showed 25 live births in all groups, two of which with TGA died postnatally; one of the newborns was trisomy 21 . Of the remaining newborns, 22 (88\%) had normal postnatal neurologic development. Similarly, Sanhal et al. (5) reported that $90 \%$ of fetuses (euploid 
and structurally normal) with septated cystic hygroma had normal neurologic outcomes.

Other than fetal karyotyping, chromosomal microarray analysis (CMA) is an advanced technology with the ability to survey the entire genome and to identify chromosomal abnormalities, submicroscopic genomic alterations. Increased nuchal translucency and cystic hygroma are associated with different conditions, aneuploidy and structural abnormalities. Shaffer et al. (15) reported that the detection rate of CMA for fetuses with cystic hygroma was $17.1 \%$. CMA should be offered for any patient undergoing invasive sampling to identify all clinically significant alterations.

Though previous studies focused on cases with karyotyping, our study also investigated cystic hygroma with unknown karyotype in the prenatal period. The refusal rate of karyotyping was higher (19.8\%) than in the published data from European countries; this condition might be due to lower sociocultural levels and religious beliefs. We think our findings may be helpful to physicians providing parental counseling for women who refuse karyotype analysis. In fetuses with cystic hygroma with normal karyotype and in whom no structural malformations are present, pregnancy outcomes may be favorable as reported in the literature (5).

The small number of cases with cystic hygroma and unknown karyotype in 21 cases are the main limitations of this study.

\section{Conclusion}

The presence of cystic hygroma carries a high risk for aneuploidy and major structural malformations. Invasive prenatal karyotyping procedures, fetal echocardiographic examination, and parental counselling are necessary for the prediction of the prognosis. Until multicenter and large-sample sized studies have been published, these results might be helpful in providing parental counselling for those with fetal cystic hygroma.

Ethics Committee Approval: All procedures involved performed in studies involving animals and humans were in accordance with the ethical standards of the institution or practice at which the studies were conducted.

Informed Consent: It was retrospective- designed. We didn't have the informed consent forms signed.

Peer-review: Externally peer-reviewed.

Author Contributions: Surgical and Medical Practices Ş.Ç., E.Ş.Ç.; Concept - A.T.Ç., Y.E.Ü.; Design - B.Y., Ş.Ç., E.C., Y.E.Ü.; Data Collection or Processing - B.Y., O.A.; Analysis or Interpretation - E.C., B.Y.; Literature Search - B.Y., O.A.; Writing - B.Y., A.T.Ç.
Conflict of Interest: The authors declare that they have no conflicts of interest.

Financial Disclosure: The authors declared that this study received no financial support.

\section{References}

1. Malone FD, Ball RH, Nyberg DA, Comstock CH, Saade GR, Berkowitz RL, et al. First- trimester septated cystic hygroma: prevalence, natural history, and pediatric outcome. Obstet Gynecol 2005; 106:288-94.

2. Gedikbaşı A, Oztarhan K, Aslan G, Demirali O, Akyol A, Sargın A, et al. Multidisciplinary approach in cystic hygroma: prenatal diagnosis, outcome and postnatal follow-up. Pediatr Int 2009; 51:670-7.

3. Chen CP, Liu FF, Jan SW, Lee CC, Town DD, Lan CC. Cytogenetic evaluation of cystic hygroma associated with hydrops fetalis, oligohydramnios or intrauterine fetal death: the roles of amniocentesis, postmortem chorionic villus sampling and cystic hygroma paracentesis. Acta Obstet Gynecol Scand 1996; 75:454-8.

4. Economides DL, Whitlow BJ, Kadir R, Lazanakis M, Verdin SM. First trimester sonographic detection of chromosomal abnormalities in an unselected population. Br J Obstet Gynaecol 1998; 105:58-62.

5. Sanhal CY, Mendilcioğlu I, Ozekinci M, Yakut S, Merdun Z, Simsek $\mathrm{M}$, et al. Prenatal management, pregnancy and pediatric outcomes in fetuses with septated cystic hygroma. Braz J Med Biol Res 2014; 47:799-803.

6. Yakistiran B, Katlan DC, Yuce T, Soylemez F. Prenatal diagnosis and fetal outcomes of cystic hygroma: Experience of a tertiary hospital. Gynecol Obstet Reprod Med 2019; 25:4-6.

7. Bilardo CM, Pajkrt E, de Graaf I, Mol BW, Bleker OP. Outcome of fetuses with enlarged nuchal translucency and normal karyotype. Ultrasound Obstet Gynecol 1998; 11:401-6.

8. Howarth E, Draper ES, Budd JL, Konje JC, Clarke M, Kurinczuk JJ. Population-based study of the outcome following the prenatal diagnosis of cystic hygroma. Prenat Diagn 2005; 25:286-91.

9. Kharrat R, Yamamoto M, Roume J, Couderc S, Vialard F, Hillion $\mathrm{Y}$, et al. Karyotype and outcome of fetuses diagnosed with cystic hygroma in the first trimester in relation to nuchal translucency thickness. Prenat Diag 2006; 26:369-72.

10. Bernard P, Chabaud JJ, Le Guern H, Le Bris MJ, Boog G. Cystic hygroma of the neck. Antenatal diagnosis, prognostic factors, management 42 cases. J Gynecol Obstet Biol Reprod (Paris) 1991; 20:487-95.

11. Izquierdo L, Kushnir O, Sanchez D, Curet L, Olney P, Sarto GE, et al. Prenatal diagnosis of Noonan's syndrome in a female infant with spontaneous resolution of cystic hygroma and hydrops. West J Med 1990; 152:418-21.

12. Fujita $Y$, Satoh $S$, Nakayama $H$, Taguchi T, Suita $S$, Nakano H. In utero evaluation and the long-term prognosis of living infants with cystic hygroma. Fetal Diagn Ther 2001; 16:402-6.

13. Özcan HÇ, Uğur MG, Balat Ö, Sucu S, Bayramoğlu Tepe N, Öztürk E, et al. Analysis of cystic hygroma diagnosed in the prenatal period:5 years's experience at a tertiary hospital in Southeastern Turkey. J Matern Fetal Neonatal Med 2019; 32:1800-5.

14. Sparks TN, Thao K, Lianoglou BR, Boe NM, Bruce KG, Datkhaeva I, et al. Nonimmune hydrops fetalis: identifying the underlying genetic etyology. Genet Med 2019; 21:1339-44.

15. Shaffer LG, Rosenfeld JA, Dabell MP, Coppinger J, Bandholz AM, Ellison JW, et al. Detection rates of clinically significant genomic alterations by microarray analysis for specific anomalies detected by ultrasound. Prenat Diagn 2012; 32:986-95. 